\title{
Isolation of Biofilm Producing Methicillin-Resistant Staphylococcus aureus from Hospitalized Orthopaedic Patients in Kano State, Nigeria
}

\author{
${ }^{* 1}$ D. A. Oche, ${ }^{2}$ U. Abdulrahim, ${ }^{3}$ A. S. Oheagbulem and ${ }^{1}$ B. O. Olayinka \\ 1Department of Pharmaceutical Microbiology, Faculty of Pharmaceutical Sciences, Ahmadu Bello University, Zaria-Nigeria \\ 2Department of Pharmaceutics and Pharmaceutical Microbiology, Faculty of Pharmacy, University of Maidugri, Borno State, Nigeria \\ ${ }^{3}$ Department of Medical Microbiology and Parasitology, Faculty of Medicine, Nnamdi Azikiwe University, Nnewi, Anambra State, \\ Nigeria
}

[Corresponding Author: E-mail: ochedominic1@gmail.com; - P+234(0)7036050048]

\section{ABSTRACT}

Biofilm formation and resistance to methicillin are among the factors that makes Staphylococcus aureus a very important human pathogen in both health-care and community settings. This study investigated methicillin-resistance among biofilm-producing $S$. aureus isolated from 49 orthopaedic in-patients within a 3 months period. Wound swabs, nasal swabs, bed swabs and urine samples were collected from each patient. The samples were cultured and screened for presence of $S$. aureus while the micro-titre plate method was used to detect biofilm producing isolates. PCR technique was finally used to detect the presence of mecA gene in methicilin resistant S. aureus (MRSA) isolates. Findings reveal $14.8 \%$ of bacterial isolates were Staphylococcus aureus of which $96.4 \%$ were biofilm-producers. However, strong biofilm producers constitute $11.1 \%$. The mecA gene was detected in $15.8 \%$ of the MRSA isolates. Therefore, MRSA among biofilm-producing $S$. aureus is a potential threat primarily to the community of National Orthopaedic Hospital Dala and a major public health challenge.

Keywords: Biofilm, Methicillin-resistance Staphylococcus aureus (MRSA), mecA gene, Orthopaedic patients

\section{INTRODUCTION}

Staphylococcus aureus isolates that are resistant to the isoxazoyl-penicillins such as methicillin, oxacillin and flucloxacillin are regarded as methicillin resistant Staphylococcus aureus (MRSA). These MRSA isolates have shown cross-resistance to all licensed $\beta$-lactam antibiotics (Loomba et al., 2010). The expression of methicillin resistance in $S$. aureus strains is by virtue of acquired penicillin binding protein PBP2a, encoded by mecA gene (Chambers, 1999). Many MRSA isolates have the capacity to form biofilms through an icaADBG-independent mechanism, such as fibronectin-binding proteins $A$ and $B$ (FnbpA and $F n b p B)$, as well as major autolysin (Tong et al., 2015). Methicillin-resistant Staphylococcus aureus has been implicated in nosocomial infections, including orthopaedic infections (Hideki et al., 2016).

Biofilm describes the association of microorganisms in which the cells adhere to each other on a living or non-living surface within a self-produced matrix of extracellular polymeric substances (Jamal et al., 2015). Biofilms exhibit altered phenotype with regard to growth, gene expression and protein production (Donlan and Costerton, 2002). Biofilms confers protection to bacteria from stress or stimuli by providing a thick layer of extracellular proteins (Costerton, 1984; Chino et al., 2017). A bacterial biofilm is formed through initial and irreversible attachment, microcolony formation, biofilm maturation, and biofilm dispersion (Wei and Ma, 2013). Biofilm matrix is known to be made of polysaccharides, proteins, and nucleic acids that can be dissolved by enzymatic degradation (Fong and Yildiz, 2015). Proteinaceous components, such as the nonribosomally generated peptide aureusimine (phevalin) in Staphylococcus aureus (Paharik and Horswill, 2016) and three exopolysaccharides (Psl, Pel, and alginate) in Pseudomonas aeruginosa (Wei and Ma, 2013; Fong and Yildiz, 2015) play important roles in 


\section{Nigerian Journal of Basic and Applied Science (June, 2020), 28(1): 66-74}

helping to maintain biofilm structure and confer resistant to antibiotics and disinfectants.

Many implant-based and chronic infections including those involving prosthetic heart valves, central venous catheters, urinary catheters, orthopaedic prostheses, penile prostheses, endocarditis, otitis media, osteomyelitis and sinusitis have been associated with Staphylococcus aureus biofilms (Costerton et al., 1999; Bendouah et al., 2006). Biofilm infections are difficult to treat, and in vitro susceptibility tests have shown that biofilms are considerably more resistant than planktonic cells to the action of antibiotics (Mohamed et al., 2007). The mechanisms responsible for this resistance include the physical and chemical diffusion barrier formed by the exopolysaccharide matrix which hinders antimicrobial penetration, the existence of micro environments that antagonize the antibiotic action, the activation of stress responses that cause changes in bacterial physiology, and the stable and slower growth of these microorganisms due to nutrient limitation and the absence of antimicrobial targets (Coelho et al., 2011). Initially, high resistance of biofilm bacteria to antibiotics was attributed to reduced drug penetration into the biofilm core caused by a physical barrier formed of extra-cellular polymeric substance (Suci et al., 1994). However, reduced bacteria growth rate, active starvation response and changes in bacterial gene expression also contribute to biofilm resistance (Marque's et al., 2015), making biofilm-associated infection very difficult to overcome.

Antimicrobials such as beta-lactams are preferred for the treatment of staphylococcal infections. However, production of betalactamase enzymes, coded by blaz that hydrolyzes the beta-lactamic ring, and production of low-affinity penicillin binding protein (PBP2a), coded by mecA, may lead to antimicrobial resistance (Pehlivanoglu and Yardimci, 2012). These resistance genes can be acquired by bacteria via horizontal gene transfer (HGT). A very important process resulting to the emergence of new resistant pathogen is conjugative plasmid-mediated HGT (Schiwon et al., 2013). Biofilm provides an ideal environmental situation for conjugation to occur between bacteria within the biofilms, thereby allowing the exchange of genetic materials between them (Águila-Arcos et al., 2018). Also, bacterial conjugation can induce biofilm formation since the cell-to-cell contact required for gene exchange is favored by the close proximity of bacteria required for biofilm formation (D'Alvise et al., 2010). This link between biofilms and bacterial conjugation increases both the risk of biofilm-related infections and the spread of virulence factors. In this study, we investigated the capability of Staphylococcus aureus isolated from orthopaedic patients on admission to produce biofilm as well as determine methicillinresistance among these biofilm-producing Staphylococcus aureus

\section{MATERIALS AND METHODS Sample Collection}

Ethical approval was obtained from the hospital's Ethical Committee for the purpose of this research and informed consent was obtained from each patient. The sample size was determined according to methods described by Kadam and Bhalerao (2010) and a total of 49 patients on admission in the National Orthopaedic Hospital Dala (NOHD), Kano were recruited for this study. The gender and age of each patient was noted and recorded. From each patient, 4 categories of samples were collected: mid-stream Urine $(U)$, wound swab $(\mathrm{W})$, nasal swab $(\mathrm{N})$ and patient's bed swab (B). A total of 189 samples were collected and were numbered serially. Samples collected were transported in sterile ziploc (plastic) bags contained in ice packs to the Microbiology Laboratory, Department of Pharmaceutical Microbiology, Faculty of Pharmaceutical Sciences, Ahmadu Bello University Zaria. 


\section{Staphylococcus aureus Isolation and Identification}

The clinical samples were inoculated into freshly prepared nutrient broth (Oxoid Ltd., Basingstoke, Hampshire, England) and incubated at $37^{\circ} \mathrm{C}$ for $24 \mathrm{~h}$. A loop-full of growth from the nutrient broth medium was streaked onto Mannitol Salt Agar (Oxoid Ltd., Basingstoke, Hampshire, England) and incubated for $24 \mathrm{~h}$ at $37^{\circ} \mathrm{C}$ (Public Health England, 2017). Discrete, round, single, goldenyellow colonies were presumptively identified as Staphylococci. The isolates were characterized by conducting the following tests: gram stain, catalase, coagulase (Ochei and Kolhatkar, 2008; Chandra and Mani, 2011). Microgen ${ }^{\text {TM }}$ Staph-ID System was used to identify the isolates.

\section{Detection of Biofilm Producing Staphylococcus aureus Isolates}

The micro-titre plate method as modified by Merrit et al. (2005) was used to screen for biofilm producing Staphylococcus aureus isolates. The cells were grown for $24 \mathrm{~h}$ at $37^{\circ} \mathrm{C}$ in $2 \%$ glucose and $2 \%$ sucrose supplemented Brain Heart Infusion (BHI) broth (Oxoid Ltd., Basingstoke, Hampshire, England). After preparing 1:100 $\mu$ l dilution of the cells in supplemented $\mathrm{BHI}$ broth, $150 \mu \mathrm{l}$ of the cell suspension was used to inoculate sterile flat-bottomed, 96-well polystyrene micro-titre plate in triplicate and 150 $\mu$ of un-inoculated supplemented BHI broth was dispensed into three wells of the micro-titre plate to serve as control. The micro-titre plate was then incubated for $48 \mathrm{~h}$ at $37^{\circ} \mathrm{C}$. After incubation, the suspension was poured off and the wells washed three times in normal saline to remove unfixed microbial cell then allowed to dry in an inverted position. The dried wells were subsequently stained with $250 \mu \mathrm{l}$ of $0.1 \%$ crystal violet solution and incubated $25^{\circ} \mathrm{C}$ for 20 minutes. The excess stain was poured off and wells washed three (3) times with normal saline and dried for 30 minutes at $25^{\circ} \mathrm{C}$. Positive results were seen as the presence of a layer of stained materials adhered to the inner wall of the wells.
Biofilm was quantified by first reconstituting the microtitre plate with $250 \mu$ l of ethanol:acetic acid (95:5 v/v) after which $100 \mu$ l was transferred to a new microtitre plate. Absorbance (OD) was read at $630 \mathrm{~nm}$ using a microplate reader. Absorbance of the uninocluted wells (negative control) was used to calculate the cut off $(\mathrm{ODc})$ as follows:

$\mathrm{ODC}=$ Average $\mathrm{OD}$ value of negative control +3 $x$ standard deviations of negative control.

The ODc value was used to classify biofilm producing capability of isolates into four categories: non-adherent $(\mathrm{OD}<\mathrm{ODc})$, weakly adherent $(\mathrm{ODc}<\mathrm{OD}<2 \times \mathrm{ODc})$, moderately adherent $(2 \times \mathrm{ODc}<\mathrm{OD}<4 \times \mathrm{ODc})$, and strongly adherent $(4 \times \mathrm{ODc}<\mathrm{OD})$ (Stepanovic et al., 2007).

Detection of mecA Gene in MethicillinResistant Staphylococcus aureus Isolates

Biofilm producing isolates were subjected to agar-disc diffusion method (EUCAST, 2018) for antibiotic susceptibility test using $30 \mu \mathrm{g}$ cefoxitin disc (Oxoid Ltd., Basingstoke, Hampshire, England) to determine methicillin resistance Nine phenotypically methicillin-resistant $S$. aureus (MRSA) strains were randomly selected as representatives of the nineteen (19) phenotypical MRSA isolates for polymerase chain reaction (PCR). Briefly, genomic DNA was extracted using Qiagen genomic DNA extraction kit, from an overnight MRSA culture. A $25 \mu$ reaction mix was prepared in microfuge tubes containing 12.5 $\mu \mathrm{l}$ master mix (Biolabs), $1 \mu \mathrm{l}$ each of forward and reverse mecA primer (5'-AAA ATC GAT GGT AAA GGT TGG $C$-3' and 3'- AGT TCT GCA GTA CCG GAT TTG C $-5^{\prime}$ ) respectively with a base pair of 533bp (Inqaba Biotec), $5.5 \mu l$ nuclease free water and $5 \mu \mathrm{l}$ of the extracted DNA. The tubes were votexed briefly to mix then placed in a thermal cycler (Applied Biosystem 9700) for DNA amplification using the following PCR cycling protocol: initial denaturation at $94^{\circ} \mathrm{C}$ for 5 minutes, followed by 35 cycles of denaturation at $94^{\circ} \mathrm{C}$ for 30 seconds, annealing at $55^{\circ} \mathrm{C}$ for 1 minute, an extension at $72^{\circ} \mathrm{C}$ for 1 minute and final extension at $72^{\circ} \mathrm{C}$ for 7 minutes. PCR 
products (amplicons) were electrophoresed on $1.5 \%$ agarose gel and visualized after ethidium bromide staining on a UV trans-illumination gel documentation system (Bio-Rad).

\section{Data Analysis}

Data was presented as mean \pm standard deviation and percentages were calculated where necessary. Results of Staphylococcus aureus and MRSA distribution are presented as bar-charts and in tabular form while PCR electrophoretogram was presented as plates.

\section{RESULTS}

Table 1 presents summary of gender and ages of selected subjects for this study. Male participants were $42(85.7 \%)$, while $7(14.3 \%)$ were female. Among these participants, $3(6.1 \%)$ were within 1 - 17 years, $38(77.6 \%)$ were within $18-40$ years and $8(16.3 \%)$ were above 40 years. Table 1 also shows the age distribution of participants in this study.

\section{Identification of Staphylococcus aureus and biofilm producers}

Twenty eight (28) samples were positive for Staphylococcus aureus out of which $2(7.1 \%)$ were from bed swabs, $12(42.9 \%)$ were from wound swabs, $8(28.6 \%)$ were from nasal swabs, while $6(21.4 \%)$ were isolated from urine. Classification of biofilm producing strains is presented in Table 2. Twenty seven (27) isolates (96.4\%) had biofilm production capabilities and the distribution showed that most of the biofilm producing strains (12 or $42.9 \%$ ) were wound sample isolates. However $64.3 \%$ of all the biofilm producing isolates were weak biofilm Producers.

\section{Methicillin Resistance in Biofilm Producing Staphylococcus aureus Isolates}

Out of the 27 biofilm producing $S$. aureus isolates tested for phenotypic expression of methicillin resistance, $19(67.9 \%)$ of the isolates were MRSA while 9 (32.1\%) were methicillin susceptible $S$. aureus (MSSA). Distribution of the MRSA and MSSA isolates across the sample collected is shown in Figure 1.

Table 1: Demography of Patients that Participated in this Study.

\begin{tabular}{cccc}
\hline Age Range in & \multicolumn{2}{c}{ Percentage of Patients Recruited } & All Patients \\
\cline { 2 - 3 } Years & Male & Female & \\
\hline $1-17$ & $2(4.1 \%)$ & $1(2 \%)$ & $3(6.1 \%)$ \\
$18-40$ & $32(65.3 \%)$ & $6(12.3 \%)$ & $38(77.6 \%)$ \\
$41-$ above & $8(16.3 \%)$ & $0(0)$ & $8(16.3 \%)$ \\
\hline Total & $42(85.7 \%)$ & $7(14.3 \%)$ & $49(100 \%)$ \\
\hline
\end{tabular}

Table 2: Classification and Distribution of Biofilm Produced by the $S$. aureus Isolates.

\begin{tabular}{lccccc}
\hline Biofilm Production & Bed & Wound & Nasal & Urine & All Samples \\
\hline Non Biofilm Producer & $0(0 \%)$ & $0(0 \%)$ & $1(12.5 \%)$ & $0(0 \%)$ & $1(3.6 \%)$ \\
Weak Biofilm Producer & $1(50 \%)$ & $8(66.7 \%)$ & $6(75 \%)$ & $3(50 \%)$ & $18(64.3 \%)$ \\
Moderate Biofilm Producer & $0(0 \%)$ & $3(25 \%)$ & $0(0 \%)$ & $3(50 \%)$ & $6(21.4 \%)$ \\
Strong Biofilm Producer & $1(50 \%)$ & $1(8.3 \%)$ & $1(12.5 \%)$ & $0(0 \%)$ & $3(10.7 \%)$ \\
\hline Total & $\mathbf{2 ( 7 . 1 \% )}$ & $\mathbf{1 2 ( 4 2 . 9 \% )}$ & $\mathbf{8 ( 2 8 . 6 \% )}$ & $\mathbf{6 ( 2 1 . 4 \% )}$ & $\mathbf{2 8 ( 1 0 0 \% )}$ \\
\hline
\end{tabular}




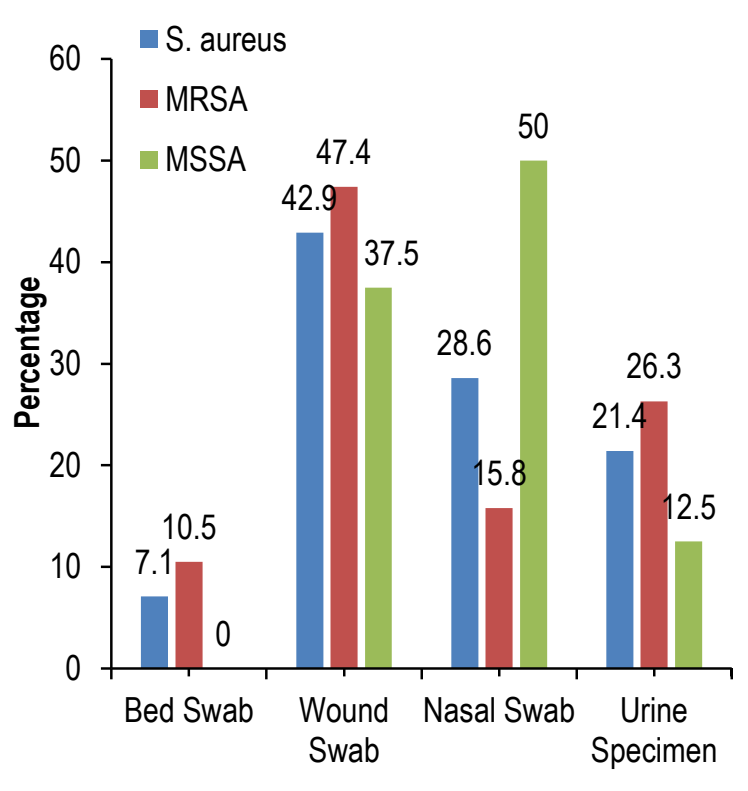

Figure 1: Distribution of Staphylococcus aureus, MRSA and MSSA Isolates by Specimen.

The mecA gene was detected in 3 of the 9 randomly selected biofilm producing MRSA isolates. The $m e c A$ genes detected were all from wound swap samples (Plate 2).

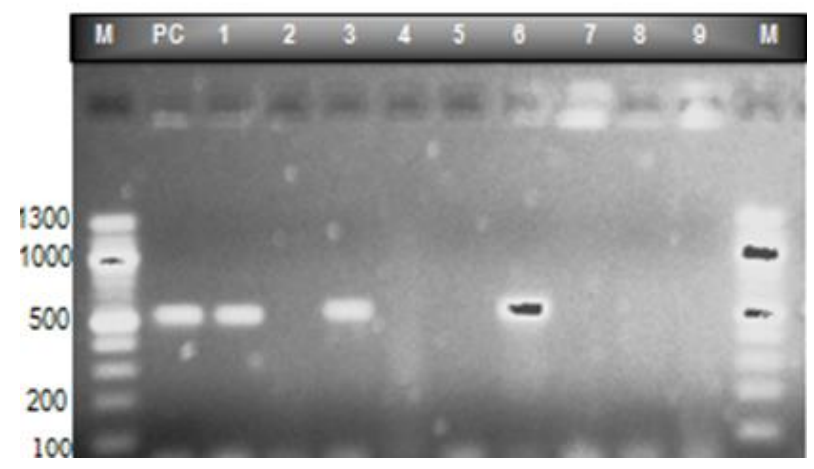

Plate 2: Electrophoretograph of Amplified mecA gene (533bp) Staphylococcus aureus Isolates. Key: Lane PC: Positive Control; Lane 1: 49W; Lane 2:33U; Lane 3: 23W;Lane 4: 46B; Lane 5: 7N; Lane 6: 26W; Lane 7: 50W; Lane 8:24U; Lane 9: 3W; Lane M: 100bp Molecular DNA ladder; and $\mathrm{bp}=$ Base pair.

\section{DISCUSSION}

Staphylococcus aureus are successful as commensal or pathogenic organisms because they adapt rapidly to selective pressures imparted by the human host (Malachowa and DeLeo, 2010). The highest occurrence of
Staphylococcus aureus observed in this study was within the group of 18 to 49 years, Ribeiro et al. (2013) also reported similar occurrence of Staphylococcal infection for surgical site infection in orthopaedic surgery within the age group of 18 to 48 years. Although, Crémet et al (2012) noted a higher risk in orthopaedic surgical infections among patients with ages of 50 years and above.

The highest occurrence of $S$. aureus isolates in this study was however recorded from wound swabs $(41.9 \%)$ followed by nose swab samples with $28.6 \%$. A study conducted in Adis-Ababa recorded a $14.3 \%$ occurrence of $S$. aureus in tested samples and $33.3 \%$ of the samples were nasal swabs (Dilnessa and Bitew, 2016). Colonization of patient's nasal cavity bears risk of transferring this organism to the wound, either by way of aerosols or by the patient's hands, especially when the patients fail to wash hands after coming into contact with nose cavity or while sneezing. Similarly, prolong use of bed spread could contribute to the cross contamination of wounds as this organism was demonstrated to be present on bed spreads (Figure 1). High occurrence of biofilm formers $(96.4 \%)$ reported in this study could be linked to the slow progression in wound healing process among orthopaedic patients. The biofilm matrix is known to be a vital factor in preventing antibiotics from reaching the infecting organisms within the matrix (Marque's et al., 2015), thereby conferring resistance (bacteriostatic or bactericidal) on the organisms within the biofilm matrix. Biofilm production by Staphylococcus aureus has been identified as an important factor contributing to the pathogenesis, antibiotic resistance and virulence (Stewart and Costerton, 2001). Biofilm producing Staphylococcus aureus have been implicated as causative agents in diseases including septicaemia, endocarditis, osteomyelitis and nosocomial infections caused by Staphylococcus aureus (Kim et al., 2008).

Methicillin resistant Staphylococcus aureus (MRSA) infections continues to be a serious and dreadful challenge as their prevalence is reported to be increasing exponentially (Sanders et al., 


\section{Nigerian Journal of Basic and Applied Science (June, 2020), 28(1): 66-74}

2011) especially among biofilm formers. Like other $\beta$-lactam antibiotics, methicilin interferes with the final step of cell wall biosynthesis by inhibiting the cross-linkage between peptidoglycan units that make up a major component of the cell wall of Gram positive bacteria (Kohanski et al., 2010).This study reported a high phenotypic prevalence of MRSA $(67.9 \%)$ in orthopaedic patients, and only $33.3 \%$ genetically harbour the mecA gene from the MRSA isolates. Similar findings by Adhikari et al. (2017) reported a $29.1 \%$ presence of $m e c A$ gene in $S$. aureus isolates. Absence of $m e c A$ gene in isolates classified as MRSA phenotypically could be attributed to the mecC gene that also confers resistance to methicillin. Other factors that may be responsible for the methicillin resistance is hyper-production of $\beta$-lactamase by these isolates (Adhikari et al., 2017). Olayinka et al (2009) reported the absence of mecA gene in 36 Staphylococcus aureus isolates that were phenotypically MRSA positive but were hyperproducers of the $\beta$-lactamase enzyme. Elhassan et al. (2015) also reported 61.5\% Staphylococcus aureus isolates classified as MRSA phenotypically, but did not detect presence of $m e c A$ gene in their genomic DNA.

Evidences however suggest that the mecA gene is contained in a mobile gene element called the Staphylococcal cassette chromosome mec, from which the gene can undergo horizontal gene transfer (HGT) and insert itself into the host species, (Hanssen and Ericson, 2006). Due to the proximity or adherence of bacteria (Staphylococcus aureus) cells to each other within biofilms, resistant genes that confer resistance such as the mecA gene are easily transferred from one cell to other cells through HGT, thereby making the whole biofilm community resistant to methicillin and other antibiotics .

\section{CONCLUSION}

This study detected mecA gene in MRSA among the biofilm producing Staphylococcus aureus isolated from in-patients of the National
Orthopaedic Hospital Dala (NOHD), Kano. The presence of resistant strains of Staphylococcus aureus in a clinical setting makes them a potential threat of medical importance and a major public health challenge. Therefore, regular monitoring of isolates circulating in a particular hospital or community is essential to tackle the spread of multidrug resistant pathogens like MRSA.

\section{ACKNOWLEDGEMENTS}

We are very thankful for the co-operation received from the staff of National Orthopaedic Hospital Dala, Kano State, Nigeria and Central Veterinary Research Laboratory, Faculty of Veterinary Medicine, Usmanu Danfodiyo University Sokoto, Sokoto State, Nigeria.

\section{REFERENCES}

Adhikari, R., Pant, N. D., Neupane, S., Neupane, M., Bhattarai, R., Bhatta, S., Chaudhary, R. and Lekhak, B. (2017). Detection of Methicillin Resistant Staphylococcus aureus and Determination of Minimum Inhibitory Concentration of Vancomycin for Staphylococcus aureus isolated from Pus/Wound Swab Samples of the Patients Attending a Tertiary Care Hospital in Kathmandu, Nepal. Canadian Journal of Infectious Diseases and Medical Microbiology, 2191532.

Águila-Arcos, A., Álvarez-Rodríguez, I., Garaiyurrebaso, O., Garbisu, U., Grohmann, E. and Alkorta, I. (2018). Biofilm-Forming Clinical Staphylococcus Isolates Harbor Horizontal Transfer and Antibiotic Resistance Genes. Frontiers in Microbiology, doi: 10.3389/fmicb.2017.02018

Bendouah, Z., Barbeau, J., Hamad, W. A. and Desrosiers, M. (2006). Biofilm Formation by Staphylococcus aureus and Pseudomonas aeruginosa is associated with an unfavourable evolution after surgery for chronic sinusitis and nasal polyposis. Otolaryngology in Head and Neck Surgery, 134: 991 - 996. 
Chambers, H. E. (1999). Methicillin resistance in Staphylococci: Molecular and biochemical. Clinical Microbiology Review, 10: 781-791.

Chandra, T. J. and Mani, P. S. (2011). A study of two rapid tests to differentiate Grampositive and Gram-negative aerobic bacteria. Journal of Medical and Allied Science,1: 84-85.

Chino, T., Nukui, Y., Morishita, Y. and Moriya, K. (2017). Morphological bactericidal fastacting effects of peracetic acid, a highlevel disinfectant, against Staphylococcus aureus and Pseudomonas aeruginosa biofilms in tubing. Antimicrobial Resistance and Infection Control, 6: 122 129.

Coelho, S. M. O., Pereira, I. A., Soares, L. C., Pribul, B. R. and Souza, M. M. S. (2011). Profile of virulence factors of $S$. aureus isolated from subclinical bovine mastitis in the state of Rio de Janeiro, Brazil. Journal of Dairy Science, 94(7): 3305-3310.

Costerton, J. W. (1984). The etiology and persistence of cryptic bacterial infections: a hypothesis. Revised Infectious Diseases, 6:608-616.

Costerton, J. W., Stewart, P.S. and Greenberg, E.P. (1999). Bacterial Biofilms: A Common Cause of Persistent Infections. Science, 284: 1318 - 1322.

Crémet, L., Corvec, S., Bémer, P., Bret, L., Lebrun, C., Lesimple, B., Miegeville, A. F., Reynaud, A., Lepelletier, D. and Caroff, N. (2012). Orthopaedic-implant infections by Escherichia coli: molecular and phenotypic analysis of the causative strains. Journal of Infection, 64(2): 169175.

D'Alvise, P. W., Sjoholm, O. R., Yankelevich, T., Jin, Y., Wuertz, S. and Smets, B. F. (2010). TOL plasmid carriage enhances biofilm formation and increases extracellular DNA content in Pseudomonas putida KT2440. FEMS Microbiology Letters, 312: 84-92.
Dilnessa, T. and Bitew, A. (2016). Prevalence and Antimicrobial Susceptibility Pattern of Methicillin Resistant Staphylococcus aureus Isolated from Clinical Samples at Yekatit 12 Hospital Medical College, Addis Ababa, Ethiopia. BMC Infectious Diseases, 16: 398.

Donlan, R. M. and Costerton, J. W. (2002). Biofilms: survival mechanisms of clinically relevant microorganisms. Clinical Microbiology Revised, 15:167 - 193.

Elhassan, M. M., Ozbak, H. A., Hemeg, H. A., Elmekki, M. A. and Ahmed, L. M. (2015). Absence of the mecA gene in methicillin resistant Staphylococcus aureus isolated from different clinical specimens in shendi city, Sudan. BioMed research international, 2015. http://dx.doi.org/10.1155/2015/895860

European Committee on Antimicrobial susceptibility testing (2018). Breaking points tables for interpretation of MICs and zone diameters. Version 6.0. http://www.eucast.org.

Fong, J. N. and Yildiz, F. H. (2015). Biofilm matrix proteins. Microbiology Spectra, 3: $1-27$.

Hanssen, A. M. and Ericson, S. J. U. (2006). SCC mec in Staphylococci: genes on the move. FEMS Immunology and Medical Microbiology, 46(1): 8 - 20.

Hideki, K., Kazuaki, M., Akari, S., Michiyo, O., Aya, N., Satoko, N., Hiroyuki, T., Takao, S., Setsuro, K., Koichi, T. and Junichiro, N. (2016). A Bundle that includes Active Surveillance, Contact Precaution for Carriers, and Cefazolin-Based Antimicrobial Prophylaxis Prevents Methicillin-Resistant Staphylococcus aureus Infections in Clean Orthopaedic Surgery. American Journal of Infection Control, 44(2): 210-214.

Jamal, M., Tasneem, U., Hussain, T. and Andleeb, S. (2015). Bacterial Biofilm: Its Composition, Formation and Role in Human Infections. Journal of Microbiology 


\section{Nigerian Journal of Basic and Applied Science (June, 2020), 28(1): 66-74}

and Biotechnology. 4(3) e-ISSN:23203528.

Kadam, P. and Bhalerao, S. (2010). Sample Size Calculation. International Journal of Ayurveda Research, 1(1): 55-57.

Kim, J. H., Kim, C. H., Hacker, J., Ziebuhr, W. Lee, B. K. and Cho, S. H. (2008). Molecular characterization of regulatory genes associated with biofilm variation in a Staphylococcus aureus strain," Journal of Microbiology Biotechnology, 18(1): 2834.

Kohanski, M. A., Dwyer, D. J. and Collins, J. J. (2010). How antibiotics kill bacteria: from targets to networks. Nature Review Microbiology, 8(6): 423-435.

Loomba P. S., Taneja J. and Mishra B. (2010). Methicillin and Vancomycin Resistant Staphylococcus aureus in Hospitalized Patients. Journal of Global Infectious Diseases, 2(3): 275 - 283.

Malachowa, N. and DeLeo, F. R. (2010) Mobile genetic elements of Staphylococcus aureus. Cellular and Molecular Life Sciences, 67: 3057-3071.

Marque 's, C., Tasse, J., Pracros, A., Collin, V., Franceschi, C., Laurent, F., Chatellier, S. and Forestier, C. (2015). Effects of antibiotics on biofilm and unattached cells of a clinical Staphylococcus aureus isolate from bone and joint infection. Journal of Medical Microbiology, 64: 1021 - 1026.

Merritt, J. H., Kadouri, D. E. and O'Toole, G. A. (2005). Growing and Analysing Static Biofilms. Current Protocols in Microbiology. 1B.1.1-1B.1.17

Mohamed, J. A., Huang, D. B., Jiang, Z., DuPont, H. L., Nataro, J. P., Belking-Gerson, J. and Okhuysen P. C. (2007). Association of Putative Enteroaggregative Escherichia coli Virulence Genes and Biofilm

Production in Isolates from Travellers to Developing Countries. Journal of Clinical Microbiology, 45:121-126.

Ochei, J. O. and Kolhatkar, A. A. (2000) Medical Laboratory Science: theory and practice, 7th reprint 2008, Tata. McGraw- Hill Publishing Co. Ltd. 2008; 644-674.

Olayinka, B. O., Olayinka, A. T., Obajuluwa, A. F., Onaolapo, J. A. and Olurinola, P. F. (2009). Absence of mecA gene in methicillin-resistant staphylococcus aureus isolates. African Journal of Infectious Diseases, 3(2): 49 - 56 .

Paharik, A. E. and Horswill, A. R. (2016). The staphylococcal biofilm: adhesins, regulation, and host response. Microbiology Spectra, 4: 1- 48 .

Pehlivanoglu, F. and Yardimci, H. (2012). Detection of methicillin and vancomycin resistance in Staphylococcus strains isolated from bovine milk samples with mastitis. Kafkas Universitesi Veteriner Fakultesi Dergisi, 18(5): 849-855.

Public Health England (2017). Inoculation of culture media for bacteriology.UK Standards for Microbiology Investigations. Q 5 Issue no: 2.

Ribeiro, J. C., dos Santos, C. B., Bellusse, G. C., Rezende, V. D., Galvão, C. M. (2013). Occurrence and Risk Factors for Surgical Site Infection in Orthopaedic Surgery. Acta Paulista de Enfermagem, 26(4):103.

Sanders, R. C., Diokno, R. M. and Romero, J. (2011). MRSA infections in children. Journal of the Arkansas Medical Society, 107: 288-290.

Schiwon, K., Arends, K., Rogowski, K. M., Fürch, S., Prescha, K., Sakinc, T., Houdt, R. B., Werner, G. and Grohmann, E. (2013). Comparison of antibiotic resistance, biofilm formation and conjugative transfer of Staphylococcus and Enterococcus isolates from International Space Station and Antarctic Research Station Concordia. Microbial Ecology, 65: 638651.

Stepanovic, S., Vukovi_c, D. And Hola, V. (2007). Quantification of Biofilm in Microtitre Plates: Overview of Testing Conditions and Practical Recommendations for Assessment of Biofilm Production by Staphylococci, Acta 
Oche et al: Isolation of Biofilm Producing Methicillin-Resistant Staphylococcus Aureus from....

Pathologica Mmicrobiologica et Immunologica Scandinavica, 115: 891899.

Stewart, P. S. and Costerton, J. W. (2001). Antibiotic resistance of bacteria in biofilms," The Lancet, 358(9276): 135138.

Suci, P. A., Mittelman, M. W., Yu, F. P. and Geesey, G. G. (1994). Investigation of Ciprofloxacin Penetration into Pseudomonas aeruginosa Biofilms. Antimicrobial Agent and Chemotherapy, 38: 2125 - 2133.
Tong S. Y., Davis J. S., Eichenberger E., Holland T. L. and Fowler V. G. (2015). Staphylococcus aureus infections: epidermiology, pathophysiology, clinical manifestations, and management. Clinical Microbiology Reviews, 28(3): 603 - 661.

Wei, Q. and Ma, L. Z. (2013). Biofilm matrix and its regulation in Pseudomonas aeruginosa. International Journal of Molecular Sciences, 14: 20983-21005. 